\title{
Positive strategies men regularly use to prevent and manage depression: a national survey of Australian men
}

Judy Proudfoot ${ }^{*}$, Andrea S. Fogarty ${ }^{1}$, Isabel McTigue ${ }^{1}$, Sally Nathan², Erin L. Whittle ${ }^{1}$, Helen Christensen ${ }^{1}$, Michael J. Player', Dusan Hadzi-Pavlovic ${ }^{1,3}$ and Kay Wilhelm ${ }^{3,4}$

\begin{abstract}
Background: Men are at greater risk than women of dying by suicide. One in eight will experience depression a leading contributor to suicide - in their lifetime and men often delay seeking treatment. Previous research has focused on men's use of unhelpful coping strategies, with little emphasis on men's productive responses. The present study examines the positive strategies men use to prevent and manage depression.

Method: A national online survey investigated Australian men's use of positive strategies, including 26 strategies specifically nominated by men in a previous qualitative study. Data were collected regarding frequency of use or openness to using untried strategies, depression risk, depression symptoms, demographic factors, and other strategies suggested by men. Multivariate regression analyses explored relationships between regular use of strategies and other variables.
\end{abstract}

Results: In total, 465 men aged between 18 and 74 years participated. The mean number of strategies used was 16.8 (SD 4.1) for preventing depression and 15.1 (SD 5.1) for management. The top five prevention strategies used regularly were eating healthily (54.2\%), keeping busy (50.1\%), exercising (44.9\%), humour (41.1\%) and helping others (35.7\%). The top five strategies used for management were taking time out (35.7\%), rewarding myself (35.1\%), keeping busy (35.1\%), exercising (33.3\%) and spending time with a pet (32.7\%). With untried strategies, a majority (58 \%) were open to maintaining a relationship with a mentor, and nearly half were open to using meditation, mindfulness or gratitude exercises, seeing a health professional, or setting goals. In multivariate analyses, lower depression risk as measured by the Male Depression Risk Scale was associated with regular use of self-care, achievement-based and cognitive strategies, while lower scores on the Patient Health Questionnaire-9 was associated with regular use of cognitive strategies.

Conclusions: The results demonstrate that the men in the study currently use, and are open to using, a broad range of practical, social, emotional, cognitive and problem-solving strategies to maintain their mental health. This is significant for men in the community who may not be in contact with professional health services and would benefit from health messages promoting positive strategies as effective tools in the prevention and management of depression.

Keywords: Men, Depression, Prevention, Management, Positive strategies

\footnotetext{
* Correspondence: j.proudfoot@unsw.edu.au

'Black Dog Institute, UNSW, Sydney, Australia

Full list of author information is available at the end of the article
} 


\section{Background}

Men are four times more likely to die by suicide than women [1], with proportionally higher rates in men who are displaced and separated, unemployed, have physical illnesses and mental health disorders, particularly depression [2-4]. One in eight adult men experience depression in their lifetime [5], although major depression can be masked in males [6] and expressed as risk-taking, antisocial and externalising behaviours, such as anger, aggression, violence, risky sexual encounters, gambling, drink-driving, road rage, deliberate self-harm, or as somatic complaints [7, 8]. Sickness absences, excessive drug and alcohol use to "numb" emotional distress, and overwork to distract from problems are also common [9]. Men are also more likely to delay or avoid seeking help for mental health issues $[10,11]$. Despite recent improvements in the rates of men accessing services for mental disorders (e.g., in Australia from 32 \% in 20062007 to $40 \%$ in 2011-2012 [12]) service utilization rates are still low and a gender gap remains.

Research to date has predominantly focused on the barriers to help-seeking for men, such as the constraints imposed by social expectations of masculinity [13] and on the unhelpful responses some men make to stress, depression and crisis. Little research has investigated the positive, helpful or adaptive strategies used by men to prevent or manage depression. This was confirmed in our recent review of qualitative studies exploring men's experiences of depression and suicidal behaviour, which found that where positive strategies were mentioned, it was usually only incidental to the main focus of the paper [14].

Yet, depression is one of the most preventable mental disorders [15]. At least $22 \%$ of new cases can be prevented each year using evidence-based interventions [16] and an up to $50 \%$ prevention rate has been reported with a stepped care approach [17]. Further, according to the World Health Organization, improving self-management "may have a far greater impact on the health of the population than any improvement in specific medical treatments" [18]. Thus, there is a need to identify men's adaptive responses to depression and stress, so that public health programs can be developed and disseminated, especially to men who may otherwise avoid help-seeking. In particular, it is important to understand the strategies that men use day to day, within their behavioural repertoire, to prevent and cope with depression.

The current study aims to fill this gap by investigating the positive strategies that men use to successfully manage their mental health and wellbeing and prevent depression. Our secondary aim was to explore whether strategy use varies according to demographic factors and in particular, whether use of prevention strategies predicts depression risk and whether use of management strategies predicts depression symptoms.
The study was informed by an initial qualitative phase involving interviews and focus groups with men from a variety of backgrounds and experiences, including those with and without mental health concerns [19]. Findings indicated that men used a very broad variety of different self-help strategies for their mental health. Some of these strategies had previously been endorsed by health professionals and people with a history of depression as likely to be helpful for sub-threshold depression [20]. The qualitative data extended this by establishing those strategies which men self-nominated as most effective in maintaining their mental health and wellbeing. The men differentiated between strategies for preventing and for managing depression [19] and reported using different strategies at different times, depending on their mood and the presence or severity of symptoms. Prevention strategies identified by the male participants emphasised good physical health, pleasurable routines and social connections, while management strategies focused on problem solving, deploying additional resources and attempts to reframe their thoughts and perspectives.

Building on this preliminary phase, the current study investigates, within a national sample of men, the positive coping strategies used by men for the prevention and self-management of depression. To our knowledge, no previous study has looked at the positive coping strategies that men use spontaneously in the course of their day-to-day lives.

\section{Method}

Design

An online survey was developed using the information gained from the earlier qualitative investigation [19]. Particular strategies suggested during that investigation formed the basis for the survey questions, using the language that the men had used. Both prevention and management strategies were included. Prevention strategies were defined as strategies men use 'to keep myself feeling $O K$, or on an even keel from day to day'. Management strategies were defined as strategies used 'to pick myself up in the times I'm feeling flat or down'. The survey was in two sections: Men were asked whether they used the strategies for either prevention or management of their mental health, how frequently they used them, or their openness to using them $(0=$ 'I do this regularly'; $1=$ 'I do this occasionally'; 2 = 'I don't do this, but I think it is a good idea'; 3 = 'I don't do this and I wouldn't ever'). In the second part of the survey, participants were asked to record any additional prevention or management strategies not mentioned in the list that they found useful (see Appendix).

The survey was piloted by ten men affiliated with the lead institution, using the Think Aloud Method [21] which invites participants to verbally express their 
thought processes to a researcher while completing the survey. This enabled identification of questions requiring clarification or simplification, as well as respondent tolerance for the length and subject matter of the survey. Adaptations were made on the basis of their feedback. The final survey consisted of 26 positive prevention and management strategies, with a free text box at the end for other strategies respondents wished to add. The survey was anonymous and was delivered using QuestionPro [22], an online survey software package. Screening and completion of the survey took approximately 20-25 min.

The online survey was publicised throughout Australia, via the lead institute's professional and digital networks, including social media, a press release and promotion via several radio stations. Entry criteria were kept to a minimum to allow maximum participation and broad-ranging responding. Individuals were eligible to participate if they were: male, aged 18 years or more, resident in Australia, comfortable reading and writing in English, willing to consent online and able to access the internet.

\section{Measures \\ Demographics}

Standard demographic data were collected, including age (years), location (postcode), Indigenous status, relationship status (never married, married, de facto, separated, divorced, widowed), employment status (full-time, part-time, retired, self-employed, full-time home duties, temporarily or permanently unable to work due to illness or injury, able to work but unemployed, full-time student, other), and highest level of education received (primary, secondary, trade/technical certificate/apprenticeship, other certificate/diploma, bachelor degree, postgraduate degree). Participants also reported the number of stressful events they had experienced in the previous year $(0=$ none; $1=$ one to two; $2=$ three or more).

\section{Depression}

Depression risk was assessed using the Male Depression Risk Scale (MDRS) [23], comprised of 22 items on an eight-point scale (0-7), where participants rate how often an item applied to them in the previous month. Total scores range from 0 to 154, with Cronbach's $\alpha=.90$ in this sample. Additionally, subscale scores are calculated for six symptom domains: distress $(0-28 ; \alpha=.82)$, drug use $(0-$ $21 ; \alpha=.95)$, alcohol use $(0-28 ; \alpha=.92)$, anger and aggression $(0-28 ; \alpha=.91)$, somatic symptoms $(0-28 ; \alpha=.78)$, and risk-taking $(0-21 ; \alpha=.71)$. Depression symptoms were assessed by the Patient Health Questionnaire-9 (PHQ-9) [24]. The PHQ-9 is comprised of nine items on a fourpoint scale (0-3), rating how often in the past 2 weeks a person has been bothered by a range of symptoms. Total scores range from 0 to $30(\alpha=.91$ in this sample), with clinically significant cut-points that indicate no/minimal (0-4), mild (5-9), moderate (10-14), moderately severe (15-19) or severe (20+) depression.

\section{Risk management}

A robust risk management procedure was in place throughout the project. Participants reporting severe depression (total PHQ-9 score of 20 or more) or current suicidal ideation (score $>0$ on PHQ-9 item ix "thoughts that you would be better off dead or of hurting yourself in some way") automatically triggered the risk protocol. 'At-risk' participants were encouraged to use a special call back service which had been set up for the project. Participants provided their contact details to Lifeline via a confidential messaging service. Lifeline then contacted the participant and carried out a risk assessment with appropriate follow-up. The project's risk protocol was also triggered at a second point in the survey, based on participants' responses to a question about whether they had ever attempted to take their own life. Any participant who responded with 'yes, in the past month' automatically received a message offering them the confidential Lifeline call-back service. Participants who responded 'yes, in the past 12 months' or 'yes, but it was more than 12 months ago' received crisis line details with the recommendation that they do not hesitate to contact them if the thoughts recur.

\section{Data analysis}

All data analyses were conducted using IBM SPSS Statistics 22 [25]. For both prevention and management analyses, the 26 positive self-help strategies were categorised into five groupings: (i) self-care - strategies aimed at physical fitness and health maintenance; (ii) pleasurable activities strategies aimed at increasing pleasure; (iii) achievement strategies aimed at completing tasks, daily routines and setting goals; (iv) cognitive - strategies aimed at reframing thoughts and/or perspectives on a problem; (v) connectedness - strategies aimed at engaging with others. Analyses were based on $0=$ does not use regularly; $1=$ regularly uses. Relationships between use of these strategy groupings and demographic variables were assessed using chi-squared analyses.

For multivariate analyses, relationship status was dichotomised $(0=$ no current relationship; $1=$ current relationship), as was employment ( $0=$ not currently employed; $1=$ currently employed) and educational attainment $(0=$ no university degree; $1=$ university degree $)$. Dependent variables were (i) depression risk (MDRS) and (ii) symptoms of depression (PHQ-9). Listwise Pearson product moment correlations were used to assess bivariate relationships between the dependent variables and continuous variables. Point biserial correlations were used to assess relationships between dependent variables and 
categorical variables. Multivariate hierarchical linear regression analyses were used to assess the relationships between (1) depression risk and regular use of prevention strategies; and (2) depression symptoms and regular use of management strategies. Non-modifiable predictors (e.g., age) were entered first, and regularly used strategies were entered in the second sequence to explore their specific association with depression risk and symptoms. Four models were specified, as follows:

Model 1 Prevention: total MDRS score was entered as the dependent variable and demographic factors were added into the model to control for age, employment, education, relationship status and number of stressful events in the previous year. Model 2 Prevention: as above, with regularly used prevention strategies entered separately in a second block. Model 1 Management: total PHQ-9 score was entered as the dependent variable, and demographic factors were added to control for age, employment, education, relationship status and number of stressful events in the previous year. Model 2 Management: as above, with regularly used management strategies entered separately in a second block.

Collinearity was assessed using tolerance values of less than .1 and variance inflation factor values of more than $10[26]$.

\section{Ethics, consent and permissions}

The study was approved by the UNSW Human Research Ethics Committee (HREC13077) and all participants indicated consent by checking an online box before commencing the survey.

\section{Results}

During data collection in April and May 2014, 689 men were eligible and consented to participate. Of those, 465 men completed the survey, giving a response rate of $67 \%$. Results are presented for these 465 men. There were no significant differences between those who completed the survey and those who did not on age, marital status, education or employment (all p's > .05).

\section{Participants}

Participants ranged in age from 18 to 74 years old, with a mean age of 40.6 (SD 12.3) years. A majority (76.1\%; $n=354$ ) were employed full-time, part-time or selfemployed. More than half (56.8 \%; $n=264)$ were married or in a de facto partnership and about half $(49.0 \%$; $n=228$ ) held a bachelor degree or higher. The majority lived in metropolitan areas throughout Australia (78.1\%; $n=363$ ).

Participants' mean scores on the MDRS and its six subscales were as follows: total score ( $M$ : 40.35, SD: 1.19), distress ( $M: 15.41, S D: .331)$, drug use (M: 2.02, $S D: .226)$, alcohol use (M: 6.55, $S D: .383)$, anger and aggression
(M: 6.61, SD: .328), somatic symptoms (M: 6.16, SD: .298) and risk-taking (M: 3.62, SD: .205). With the exception of the distress subscale, which was in the mid-range, all subscale means were low, which is comparable with other samples of men recruited online [23]. Nearly a third $(32.0 \% ; n=149)$ reported no or minimal current depression on the PHQ-9, with the remainder reporting mild (32.3\%; $n=150)$, moderate $(15.5 \%, n=72)$, moderately severe $(10.8 \% ; n=50)$, or severe $(9.5 \% ; n=44)$ depression. A large majority $(93.5 \% ; n=435)$ had ever experienced depression, with $54.6 \%(n=254)$ reporting they had received treatment for depression.

\section{Use of strategies to prevent and manage depression}

Table 1 shows participants' use of prevention strategies (i.e., "to keep myself feeling $\mathrm{OK}$ or on an even keel from day to day") and Table 2 shows use of management strategies (i.e., "to pick myself up in the times I'm feeling flat or down"). The mean number of prevention strategies used was 16.8 (SD 4.1) and the mean number of management strategies used was 15.1 (SD 5.1).

\section{Prevention strategies: regular and occasional use}

The five most regularly used prevention strategies were: eating healthily ( $54.2 \% ; n=252)$, keeping myself busy $(50.1 \% ; n=233)$, exercise ( $44.9 \% ; n=209)$, using humour to reframe my thoughts/feelings (41.1\%; $n=191)$, and doing something to help another person $35.7 \% ; n=166$ ). The five most common strategies used occasionally to prevent depression were: reward myself with something enjoyable $(51.4 \% ; n=239)$, achieve something (big or small) (49.9\%; $n=232)$, remind myself everyone messes up from time to time $(49.5 \% ; n=230)$, do something to help another person ( $49 \% ; n=228)$ and distract myself from negative thoughts or feelings $(48.4 \% ; n=225)$.

In total, 14 of the 26 prevention strategies were used (regularly or occasionally) by $70 \%$ or more of the men.

\section{Additional prevention strategies}

The men in the study used free-text to report other prevention strategies that they found useful, which were not expressly mentioned in the survey. The majority of these responses fell into three main categories of (i) specific pleasurable activities, (ii) relationships and/or social connections, and (iii) improving physical health. Examples include: reading/listening to podcasts, writing (e.g., letters, journals, blogs, poetry), listening to music and playing musical instruments, travelling, watching television or films ("it allows me to forget for a few hours"), taking photographs, playing computer games, getting outdoors (e.g., "immerse myself in nature" or "sunshine and fresh air"), motor-cycle riding, fishing, having sex, masturbation, cooking, completing puzzles and taking Vitamin B and fish oil tablets. A few 
Table 1 Use of prevention strategies to 'keep myself feeling OK or on an even keel from day to day'

\begin{tabular}{|c|c|c|c|c|c|c|c|c|c|c|c|c|}
\hline & \multicolumn{2}{|c|}{$\begin{array}{l}\text { I do this } \\
\text { regularly }\end{array}$} & \multicolumn{2}{|c|}{$\begin{array}{l}\text { I do this } \\
\text { occasionally } \\
\end{array}$} & \multicolumn{2}{|c|}{$\begin{array}{l}\text { I don't do this but } \\
\text { it's a good idea } \\
\end{array}$} & \multicolumn{2}{|c|}{$\begin{array}{l}\text { I don't do this and } \\
\text { I wouldn't ever } \\
\end{array}$} & \multicolumn{2}{|c|}{ Any use } & \multicolumn{2}{|c|}{ No use } \\
\hline & $\mathrm{n}$ & $\%$ & $\mathrm{n}$ & $\%$ & $\mathrm{n}$ & $\%$ & $\mathrm{n}$ & $\%$ & $\mathrm{n}$ & $\%$ & $\mathrm{n}$ & $\%$ \\
\hline Keep myself busy & 233 & 50.1 & 182 & 39.1 & 43 & 9.2 & 7 & 1.5 & 415 & 89.2 & 50 & 10.8 \\
\hline Eat healthily & 252 & 54.2 & 154 & 33.1 & 55 & 11.8 & 4 & 0.9 & 406 & 87.3 & 59 & 12.7 \\
\hline Do something to help another person & 166 & 35.7 & 228 & 49.0 & 67 & 14.4 & 4 & 0.9 & 394 & 84.7 & 71 & 15.3 \\
\hline Achieve something (big or small) & 144 & 31.0 & 232 & 49.9 & 79 & 17.0 & 10 & 2.2 & 376 & 80.9 & 89 & 19.1 \\
\hline Accept my sad feelings/'this too will pass' & 152 & 32.7 & 223 & 48.0 & 73 & 15.7 & 17 & 3.7 & 375 & 80.7 & 90 & 19.3 \\
\hline Reward myself with something enjoyable & 133 & 28.6 & 239 & 51.4 & 87 & 18.7 & 6 & 1.3 & 372 & 80 & 93 & 20 \\
\hline Use humour to reframe my thoughts and/or feelings & 191 & 41.1 & 179 & 38.5 & 76 & 16.3 & 19 & 4.1 & 370 & 79.6 & 95 & 20.4 \\
\hline Exercise & 209 & 44.9 & 153 & 32.9 & 96 & 20.6 & 7 & 1.5 & 362 & 77.8 & 103 & 22.2 \\
\hline Distract myself from negative thoughts and/or feelings & 135 & 29.0 & 225 & 48.4 & 80 & 17.2 & 25 & 5.4 & 360 & 77.4 & 105 & 22.6 \\
\hline Notice my thoughts and try to change my perspective & 142 & 30.5 & 216 & 46.5 & 93 & 20.0 & 14 & 3.0 & 358 & 77.0 & 107 & 23.0 \\
\hline Take some time out & 133 & 28.6 & 223 & 48.0 & 100 & 21.5 & 9 & 1.9 & 356 & 76.6 & 109 & 23.4 \\
\hline Remind myself everyone messes up from time to time & 123 & 26.5 & 230 & 49.5 & 90 & 19.4 & 22 & 4.7 & 353 & 76.0 & 112 & 24.0 \\
\hline Hang out with people who are positive & 143 & 30.8 & 207 & 44.5 & 97 & 20.9 & 18 & 3.9 & 350 & 75.3 & 115 & 24.7 \\
\hline $\begin{array}{l}\text { Talk to people close to me, or someone I trust, } \\
\text { about a problem }\end{array}$ & 136 & 29.2 & 211 & 45.4 & 105 & 22.6 & 13 & 2.8 & 347 & 74.6 & 118 & 25.4 \\
\hline Change sleeping habits & 128 & 27.5 & 183 & 39.4 & 136 & 29.2 & 18 & 3.9 & 311 & 66.9 & 154 & 23.1 \\
\hline Set goals for the future & 100 & 21.5 & 204 & 43.9 & 138 & 29.7 & 23 & 4.9 & 304 & 65.4 & 161 & 34.6 \\
\hline Having a routine/plan out my time & 129 & 27.7 & 166 & 35.7 & 131 & 28.2 & 39 & 8.1 & 295 & 63.4 & 170 & 36.6 \\
\hline Spend time with a pet & 162 & 34.8 & 93 & 20.0 & 145 & 31.2 & 65 & 14.0 & 255 & 54.8 & 210 & 45.2 \\
\hline Use positive self-talk & 71 & 15.3 & 158 & 34.0 & 167 & 35.9 & 69 & 14.8 & 229 & 49.3 & 236 & 50.7 \\
\hline Cry & 24 & 5.2 & 190 & 40.9 & 139 & 29.9 & 112 & 24.1 & 214 & 46.1 & 251 & 53.9 \\
\hline See a health professional & 75 & 16.1 & 139 & 29.9 & 190 & 40.9 & 61 & 13.1 & 214 & 46.0 & 251 & 54.0 \\
\hline Focus on my life purpose & 67 & 14.4 & 131 & 28.2 & 180 & 38.7 & 87 & 18.7 & 198 & 42.6 & 267 & 57.4 \\
\hline Join a group, club or team & 76 & 16.3 & 103 & 22.2 & 223 & 48.0 & 63 & 13.5 & 179 & 38.5 & 286 & 61.5 \\
\hline Meditate/mindfulness/gratitude & 46 & 9.9 & 124 & 26.7 & 216 & 46.5 & 79 & 17.0 & 170 & 36.6 & 295 & 63.4 \\
\hline Follow faith, religion or spirituality & 67 & 14.4 & 57 & 12.3 & 65 & 14.0 & 276 & 59.4 & 124 & 26.7 & 341 & 73.3 \\
\hline Maintain a relationship with a mentor & 30 & 6.5 & 84 & 18.1 & 271 & 58.3 & 80 & 17.2 & 114 & 24.6 & 351 & 75.4 \\
\hline
\end{tabular}

mentioned the importance of routines, such as scheduling in "me-time". Others emphasised the importance of having goals and reviewing previous achievements (e.g., "I look at all I have achieved and remind myself that a lot has changed and I am capable").

\section{Management Strategies: regular and occasional use}

The five most regularly used management strategies were: take some time out $(35.7 \% ; n=166)$, reward myself with something enjoyable (35.1\%; $n=163)$, keeping myself busy (35.1\%; $n=163)$, exercising (33.3\%; $n=155)$, and spending time with a pet (32.7\%; $n=152)$. The five most common strategies used occasionally for management were: achieve something (big or small) (46.7 \%; $n=217)$, doing something to help another person (46.5\%; $n=216)$, talking to people close to me, or someone I trust, about a problem (45.2\%; $n=210)$, cry $(44.5 \% ; n=207)$, and notice my thoughts and try to change my perspective $(43.2 \% ; n=201)$.

In total, eight of the 26 management strategies were used (regularly or occasionally) by $70 \%$ or more of the men surveyed.

\section{Additional management strategies}

Many of the activities used by the men to prevent low mood were also reported in free text as being used as management strategies (e.g., music, watching TV/films, computer games). Additional specific activities were: power walking (e.g., "exercising hard"), ignoring the problem until it has passed, looking at photos or videos from happier moments, lots of rest and 'quiet time', avoiding people or cancelling appointments until feeling better, taking time to evaluate what has gone wrong 
Table 2 Use of management strategies 'to pick myself up in the times I'm feeling flat or down'

\begin{tabular}{|c|c|c|c|c|c|c|c|c|c|c|c|c|}
\hline & \multicolumn{2}{|c|}{$\begin{array}{l}\text { I do this } \\
\text { regularly }\end{array}$} & \multicolumn{2}{|c|}{$\begin{array}{l}\text { I do this } \\
\text { occasionally } \\
\end{array}$} & \multicolumn{2}{|c|}{$\begin{array}{l}\text { I don't do this but } \\
\text { it's a good idea } \\
\end{array}$} & \multicolumn{2}{|c|}{$\begin{array}{l}\text { I don't do this and } \\
\text { I wouldn't ever } \\
\end{array}$} & \multicolumn{2}{|c|}{ Any use } & \multicolumn{2}{|c|}{ No use } \\
\hline & $\mathrm{n}$ & $\%$ & $\mathrm{n}$ & $\%$ & $\mathrm{n}$ & $\%$ & $\mathrm{n}$ & $\%$ & $\mathrm{n}$ & $\%$ & $\mathrm{n}$ & $\%$ \\
\hline Keep myself busy & 163 & 35.1 & 194 & 41.7 & 87 & 18.7 & 21 & 4.5 & 357 & 76.8 & 108 & 23.2 \\
\hline Take some time out & 166 & 35.7 & 188 & 40.4 & 96 & 20.6 & 15 & 3.2 & 354 & 76.1 & 111 & 23.9 \\
\hline Reward myself with something enjoyable & 163 & 35.1 & 182 & 39.1 & 98 & 21.1 & 22 & 4.7 & 345 & 74.2 & 120 & 25.8 \\
\hline $\begin{array}{l}\text { Talk to people close to me, or someone I trust, } \\
\text { about a problem }\end{array}$ & 128 & 27.5 & 210 & 45.2 & 101 & 21.7 & 26 & 5.6 & 338 & 72.7 & 127 & 27.3 \\
\hline Distract myself from negative thoughts and/or feelings & 134 & 28.8 & 199 & 42.8 & 104 & 22.4 & 28 & 6.0 & 333 & 71.6 & 132 & 28.4 \\
\hline Use humour to reframe my thoughts and/or feelings & 150 & 32.3 & 180 & 38.7 & 101 & 21.7 & 34 & 7.3 & 330 & 71 & 135 & 29 \\
\hline Accept my sad feelings/'this too will pass' & 150 & 32.3 & 176 & 37.8 & 108 & 23.2 & 31 & 6.7 & 326 & 70.1 & 139 & 29.9 \\
\hline Notice my thoughts and try to change my perspective & 124 & 26.7 & 201 & 43.2 & 122 & 26.2 & 18 & 3.9 & 325 & 69.9 & 140 & 30.1 \\
\hline Achieve something (big or small) & 107 & 23 & 217 & 46.7 & 121 & 26.0 & 20 & 4.3 & 324 & 69.7 & 141 & 30.3 \\
\hline Do something to help another person & 100 & 21.5 & 216 & 46.5 & 125 & 26.9 & 24 & 5.2 & 316 & 68 & 149 & 32.1 \\
\hline Remind myself everyone messes up from time to time & 116 & 24.9 & 195 & 41.9 & 124 & 26.7 & 30 & 6.5 & 311 & 66.8 & 154 & 33.2 \\
\hline Change sleeping habits & 121 & 26.0 & 182 & 39.1 & 142 & 30.5 & 20 & 4.3 & 303 & 65.1 & 162 & 34.9 \\
\hline Hang out with people who are positive & 116 & 24.9 & 182 & 39.1 & 129 & 27.7 & 38 & 8.2 & 298 & 64 & 167 & 36 \\
\hline Exercise & 155 & 33.3 & 141 & 30.3 & 148 & 31.8 & 21 & 4.5 & 296 & 63.6 & 169 & 36.4 \\
\hline Eat healthily & 129 & 27.7 & 143 & 30.8 & 163 & 35.1 & 30 & 6.5 & 272 & 58.5 & 193 & 41.5 \\
\hline Cry & 64 & 13.8 & 207 & 44.5 & 116 & 24.9 & 78 & 16.8 & 271 & 58.3 & 194 & 41.7 \\
\hline Having a routine/plan out my time & 97 & 20.9 & 152 & 32.7 & 161 & 34.6 & 55 & 11.8 & 249 & 53.6 & 216 & 46.4 \\
\hline Spend time with a pet & 152 & 32.7 & 91 & 19.6 & 154 & 33.1 & 68 & 14.6 & 243 & 52.3 & 222 & 47.7 \\
\hline See a health professional & 83 & 17.8 & 156 & 33.5 & 192 & 41.3 & 34 & 7.3 & 239 & 51.3 & 226 & 48.7 \\
\hline Use positive self-talk & 83 & 17.8 & 143 & 30.8 & 160 & 34.4 & 79 & 17.0 & 226 & 48.6 & 239 & 51.4 \\
\hline Set goals for the future & 66 & 14.2 & 154 & 33.1 & 194 & 41.7 & 51 & 11.0 & 220 & 47.3 & 245 & 52.7 \\
\hline Focus on my life purpose & 64 & 13.8 & 126 & 27.1 & 178 & 38.3 & 97 & 20.9 & 190 & 40.9 & 275 & 59.1 \\
\hline Meditate/mindfulness/gratitude & 65 & 14.0 & 111 & 23.9 & 210 & 45.2 & 79 & 17.0 & 176 & 37.9 & 289 & 62.1 \\
\hline Join a group, club or team & 58 & 12.5 & 94 & 20.2 & 220 & 47.3 & 93 & 20.0 & 152 & 32.7 & 313 & 67.3 \\
\hline Follow faith, religion or spirituality & 63 & 13.5 & 59 & 12.7 & 73 & 15.7 & 270 & 58.1 & 122 & 26.2 & 343 & 73.8 \\
\hline Contact my mentor when I'm feeling down & 33 & 7.1 & 82 & 17.6 & 269 & 57.8 & 81 & 17.4 & 115 & 24.7 & 350 & 75.3 \\
\hline
\end{tabular}

(e.g., "analyse situations, find alternate explanations for others' reaction"), trying not to worry about things, reviewing medication doses, making plans for the future for something to look forward to, "fake it until I make it", and spending time with family and pets. Answers often emphasised being gentle with oneself (e.g., "Don't push myself too hard"), taking the needed time to recuperate, and choosing interactions with others carefully (e.g., "Stay away from people who put me down").

\section{Openness to using new strategies}

Overall, respondents reported being open to using new strategies. The top five prevention strategies that the most men in the study were open to using (i.e., 'I don't do this, but I think it is a good idea') were maintaining a relationship with a mentor $(58.3 \% ; n=271)$, joining a group, club or team $(48.0 \% ; n=223)$; meditation, mindfulness or gratitude $(46.5 \% ; n=216)$, seeing a health professional (40.9 \%; $n=190)$ and focusing on life's purpose (38.7 \%; $n=180)$. The top five management strategies men did not use, but were open to using were: contacting a mentor when feeling down $(57.8 \% ; n=269)$, joining a group club or team $(47.3 \% ; n=220)$, meditation, mindfulness or gratitude $(45.2 \% ; n=210)$, setting goals for the future $(41.7 \% ; n=194)$ and seeing a health professional $(41.3 \% ; n=192)$.

\section{Strategies least likely to be used for prevention or management}

The five prevention strategies that participants did not use and were not open to using (i.e., 'I don't use this, and I wouldn't ever') were: following faith, religion or 
spirituality $(59.4 \% ; n=276)$, crying $(24.1 \% ; n=112)$, focusing on life's purpose (18.7 \%; $n=87)$, maintaining a relationship with a mentor $(17.2 \% ; n=80)$ and practicing meditation, mindfulness or gratitude $(17.0 \%$; $n=79 / 465)$. The five management strategies that the most men did not use and were not open to using were: following faith, religion or spirituality $(58.1 \% ; n=270)$, focusing on life's purpose $(20.9 \%$; $n=97)$, joining a group, club or team $(17.4 \% ; n=81)$ and using positive self-talk ( $17 \% ; n=79)$.

\section{Strategy use and demographic factors}

Table 3 shows the proportion of respondents who regularly used each of the five strategy groups for either prevention or management, broken down by age, relationship status and education level. For regularly used prevention strategies, there was a significant difference by age group in the regular use of cognitive strategies $\left(\chi^{2}=11.18, d f=4, p=.025\right)$, and a significant difference by relationship status in the regular use of pleasure-based strategies $\left(\chi^{2}=17.8, \quad d f=2, \quad p<.001\right)$. Likewise, a significant difference in regular use of self-care strategies $\left(\chi^{2}=7.80, d f=2, \quad p=.020\right)$ and achievement-based strategies $\left(\chi^{2}=8.51, d f=2, p=.014\right)$, was observed by education level.

For regularly used management strategies, significant differences were observed by age-group in the regular use of self-care strategies $\left(\chi^{2}=11.40, d f=4\right.$, $p=.022$ ), and by relationship status in the regular use of pleasurable strategies $\left(\chi^{2}=6.67, d f=2, \quad p=.036\right)$. Similarly, education levels were significantly related to differences in regular use of cognitive strategies $\left(\chi^{2}=9.33, d f=2, p=.009\right)$, and self-care strategies $\left(\chi^{2}=\right.$ 6.07, $d f=2, p=.048)$.

\section{Regularly used prevention strategies and risk of depression}

As shown in Table 4, lower MDRS scores were significantly correlated with older age, having a university degree, being in a relationship, experiencing fewer stressful events in the previous year and using self-care, achievement, cognitive or connectedness strategies regularly for prevention.

In multivariate analyses shown in Table 5, lower MDRS scores were significantly and independently associated with older age, experiencing fewer stressful events, and using self-care, achievement and cognitive strategies regularly. Model 1 Prevention was associated with $10 \%$ of the variance shown in MDRS scores. The addition of regularly used prevention strategies in Model 2 Prevention accounted for a significant change in $R^{2}$, with the final model accounting for $18 \%$ of the variance in total MDRS scores.

Table 3 Relationship between demographic variables and use of strategies for prevention and management

\begin{tabular}{|c|c|c|c|c|c|c|c|c|c|c|}
\hline \multirow[t]{2}{*}{ Demographic characteristics } & \multicolumn{5}{|c|}{ Regular use of prevention strategies } & \multicolumn{5}{|c|}{ Regular use of management strategies } \\
\hline & Self-care & Pleasure & Achievement & Cognitive & Social & Self-care & Pleasure & Achievement & Cognitive & Social \\
\hline \multicolumn{11}{|l|}{ Age } \\
\hline $18-24$ years & $78.3 \%$ & $47.8 \%$ & 65.2 & $80.4 \%$ & $69.6 \%$ & $58.7 \%$ & $58.7 \%$ & $47.8 \%$ & $76.1 \%$ & $65.2 \%$ \\
\hline 25-34 years & $77.4 \%$ & $50.4 \%$ & $67.0 \%$ & $76.5 \%$ & $77.4 \%$ & $53.0 \%$ & $59.1 \%$ & $52.2 \%$ & $71.3 \%$ & $73.0 \%$ \\
\hline $35-44$ years & $77.8 \%$ & $38.9 \%$ & $72.2 \%$ & $62.7 \%$ & $73.8 \%$ & $59.5 \%$ & $46.8 \%$ & $48.4 \%$ & $59.5 \%$ & $63.5 \%$ \\
\hline $45-54$ years & $73.3 \%$ & $41.4 \%$ & $64.7 \%$ & $62.1 \%$ & $70.7 \%$ & $69.8 \%$ & $43.1 \%$ & $52.6 \%$ & $61.2 \%$ & $62.9 \%$ \\
\hline $55+$ years & $87.1 \%$ & $41.9 \%$ & $71.0 \%$ & $72.6 \%$ & $77.4 \%$ & $74.2 \%$ & $43.5 \%$ & $45.2 \%$ & $58.1 \%$ & $66.1 \%$ \\
\hline$p$-value & .342 & .412 & .717 & $.025^{*}$ & .700 & $.022^{*}$ & .062 & .858 & .091 & .494 \\
\hline \multicolumn{11}{|l|}{ Relationship status } \\
\hline Single & $74.3 \%$ & $56.1 \%$ & $67.8 \%$ & $70.2 \%$ & $69.0 \%$ & $56.1 \%$ & $57.3 \%$ & $55.0 \%$ & $70.2 \%$ & $63.2 \%$ \\
\hline Married/de facto & $81.1 \%$ & $35.6 \%$ & $68.6 \%$ & $68.2 \%$ & $77.7 \%$ & $67.0 \%$ & $45.8 \%$ & $46.6 \%$ & $60.6 \%$ & $68.2 \%$ \\
\hline Divorced & $70.0 \%$ & $43.3 \%$ & $66.7 \%$ & $70.0 \%$ & $70.0 \%$ & $56.7 \%$ & $40.0 \%$ & $50.0 \%$ & $63.3 \%$ & $66.7 \%$ \\
\hline$p$-value & .141 & $<.001^{* *}$ & .971 & .902 & .117 & .058 & $.036^{*}$ & .233 & .125 & .556 \\
\hline \multicolumn{11}{|l|}{ Educational level } \\
\hline Secondary school or lower & $72.5 \%$ & $54.9 \%$ & $58.2 \%$ & $69.2 \%$ & $72.5 \%$ & $56.0 \%$ & $52.7 \%$ & $51.6 \%$ & $60.4 \%$ & $67.0 \%$ \\
\hline Trade certificate or diploma & $72.6 \%$ & $40.4 \%$ & $65.1 \%$ & $65.1 \%$ & $74.0 \%$ & $57.5 \%$ & $49.3 \%$ & $45.9 \%$ & $56.2 \%$ & $59.6 \%$ \\
\hline University degree & $83.3 \%$ & $41.2 \%$ & $74.1 \%$ & $71.5 \%$ & $74.6 \%$ & $68.0 \%$ & $48.7 \%$ & $51.8 \%$ & $71.1 \%$ & $70.2 \%$ \\
\hline$p$-value & $.02^{*}$ & .053 & $.014^{*}$ & .423 & .932 & $.048^{*}$ & .802 & .506 & $.009^{*}$ & .106 \\
\hline
\end{tabular}


Table 4 Bivariate correlations between depression risk, demographic factors and regularly used prevention strategies $(n=465)$

\begin{tabular}{|c|c|c|c|c|c|c|c|c|c|c|c|}
\hline & & 1 & 2 & 3 & 4 & 5 & 6 & 7 & 8 & 9 & 10 \\
\hline 1. & MDRS & - & & & & & & & & & \\
\hline 2. & Age & $-.15^{* *}$ & - & & & & & & & & \\
\hline 3. & Education & $-.13^{* *}$ & .02 & - & & & & & & & \\
\hline 4. & Relationship status & $-.13^{* *}$ & $.39^{* *}$ & .11 & - & & & & & & \\
\hline 5. & Employment & -.09 & -.01 & $.23^{* *}$ & $.15^{* *}$ & - & & & & & \\
\hline 6. & Stressful events & $.25^{* *}$ & .08 & -.09 & -.01 & $-.10^{*}$ & - & & & & \\
\hline 7. & Self-care strategies (P) & $-.19^{* *}$ & .05 & $.13^{* *}$ & .09 & .02 & -.09 & - & & & \\
\hline 8. & Pleasure strategies $(P)$ & -.03 & -.05 & -.05 & $-.19^{* *}$ & -.05 & -.01 & .00 & - & & \\
\hline 9. & Achievement strategies $(P)$ & $-.21^{* *}$ & .02 & $.13^{* *}$ & .01 & .04 & -.05 & $.10^{* *}$ & $.20^{* *}$ & - & \\
\hline 10. & Cognitive strategies $(P)$ & $-.19^{* *}$ & -.07 & .05 & -.02 & .01 & .04 & .08 & $.21^{* *}$ & $.32^{* *}$ & - \\
\hline 11. & Connectedness strategies (P) & $-.12^{* *}$ & .03 & .01 & .10 & .03 & -.02 & $.11^{*}$ & $.18^{* *}$ & $.21^{* *}$ & $.35^{* *}$ \\
\hline
\end{tabular}

MDRS = total score on men's depression risk scale; $(\mathrm{P})=$ prevention; ${ }^{*} p<.05,{ }^{* *} p<.01$. Coding for dichotomous variables: $1=$ university degree, currently partnered, currently employed

\section{Regularly used management strategies and depression} symptoms

As shown in Table 6, total PHQ-9 scores were significantly correlated with age, education level, relationship status, employment, number of stressful events and achievement and cognitive management strategies.

In multivariate analyses shown in Table 7, Model 1 Management shows that being unemployed, not tertiary educated, and experiencing more stressful events significantly predicted $18 \%$ of the variance in PHQ-9 scores. After entering regularly used management strategies in the model (Model 2 Management), the total variance explained was $22 \%$ and three factors were found be independently and significantly associated with total PHQ-9 scores. Lower depression symptoms scores were associated with being employed, having a university degree and regularly using cognitive management strategies.

\section{Discussion}

The specific focus on the positive strategies that participants use to maintain their mental health and wellbeing differentiated these findings from previous research which has predominantly highlighted men's use of negative coping strategies [10, 14, 27]. Moreover, our study highlights that men are not only prepared to use positive strategies for their mental health, but they reported that they are using these strategies - and regularly. Our results also demonstrate that the men in this study report regular use of a broad variety of strategies

Table 5 Multivariate hierarchical regression for risk of depression - MDRS ( $n=465)$

\begin{tabular}{|c|c|c|c|c|c|c|c|c|c|c|}
\hline & \multicolumn{5}{|c|}{ Model 1 prevention } & \multicolumn{5}{|c|}{ Model 2 prevention } \\
\hline & B & SE & Sig & Lower & Upper & B & SE & Sig & Lower & Upper \\
\hline Age & -.311 & .101 & $.002^{*}$ & -.509 & -.112 & -.322 & .098 & $.001^{* *}$ & -.514 & -.130 \\
\hline Employment & -2.26 & 2.77 & .415 & -7.70 & 3.18 & -2.37 & 2.67 & .375 & -7.61 & 2.87 \\
\hline Relationship & -2.74 & 2.53 & .279 & -7.71 & 2.23 & -2.14 & 2.50 & .393 & -7.04 & 2.77 \\
\hline Education & -4.75 & 2.34 & .043 & -9.34 & -.155 & -2.74 & 2.29 & .231 & -7.23 & 1.75 \\
\hline Stressful events & 9.82 & 1.75 & $.000^{* *}$ & 6.38 & 13.26 & 9.53 & 1.70 & $.000^{* *}$ & 6.20 & 12.87 \\
\hline Self-care strategies (P) & & & & & & -7.20 & 2.69 & $.008^{*}$ & -12.48 & -1.91 \\
\hline Pleasure strategies (P) & & & & & & .990 & 2.34 & .672 & -3.61 & 5.59 \\
\hline Achievement strategies (P) & & & & & & -7.08 & 2.54 & $.006^{*}$ & -12.07 & -2.09 \\
\hline Cognitive strategies (P) & & & & & & -8.67 & 2.65 & $.001^{* *}$ & -13.88 & -3.46 \\
\hline Connectedness strategies (P) & & & & & & 1.15 & 2.71 & .672 & -6.47 & 4.18 \\
\hline$R^{2}$ & & & $.107^{* *}$ & & & & & $.181^{* *}$ & & \\
\hline $\mathrm{R}^{2}$ change & & & $.107^{* *}$ & & & & & $.073^{* *}$ & & \\
\hline
\end{tabular}

${ }^{*} p<.01 ;{ }^{* *} p \leq .001$ 
Table 6 Bivariate correlations between depression symptoms, demographic factors and regularly used management strategies $(n=465)$

\begin{tabular}{|c|c|c|c|c|c|c|c|c|c|c|c|}
\hline & & 1 & 2 & 3 & 4 & 5 & 6 & 7 & 8 & 9 & 10 \\
\hline 1. & PHQ-9 & - & & & & & & & & & \\
\hline 2. & Age & $-.10^{*}$ & - & & & & & & & & \\
\hline 3. & Education & $-.23^{* *}$ & .02 & - & & & & & & & \\
\hline 4. & Relationship status & $-.18^{* *}$ & $.39^{* *}$ & $.11^{*}$ & - & & & & & & \\
\hline 5. & Employment & $-.26^{* *}$ & -.01 & $.23^{* *}$ & $.15^{* *}$ & - & & & & & \\
\hline 6. & Stressful events & $.28^{* *}$ & .08 & -.09 & -.01 & $-.10^{*}$ & - & & & & \\
\hline 7. & Self-care strategies (M) & -.04 & $.16^{* *}$ & $.11^{*}$ & $.11^{*}$ & .01 & .08 & - & & & \\
\hline 8. & Pleasure strategies (M) & .02 & $-.12^{*}$ & -.02 & -.09 & -.08 & .03 & $.13^{* *}$ & - & & \\
\hline 9. & Achievement strategies (M) & $-.10^{*}$ & -.02 & .04 & -.08 & .06 & .04 & .15 & $.20^{* *}$ & - & \\
\hline 10. & Cognitive strategies (M) & -.16 & $-.11^{*}$ & $.14^{* *}$ & -.09 & .01 & .01 & .15 & $.27^{* *}$ & $.30^{* *}$ & - \\
\hline 11. & Connectedness strategies (M) & $-.13^{* *}$ & -.02 & .08 & .05 & .06 & -.00 & .24 & $.16^{* *}$ & $.23^{* *}$ & $.26^{* *}$ \\
\hline
\end{tabular}

PHQ-9 = total score on the Patient Health Questionnaire-9; $(\mathrm{M})=$ management; ${ }^{*} p<.05,{ }^{* *} p<.01$. Coding for dichotomous variables: $1=$ bachelor degree or higher, currently partnered, currently employed

in the service of prevention and management of depression.

While recent findings indicate that a greater proportion of men are seeking help for mental health problems [12], there is still a large gap, with at least $60 \%$ of men not seeking help when it is needed and with men over-represented in death by suicide. Our results indicate that a large majority of the men surveyed do use positive strategies in tough times. This aligns with a 2010 survey of men and women, which found that $52 \%$ reported using any of four specified self-management strategies for their mental health [28]. The difference between our research and other studies is that the positive strategies we report here were identified by men, and are thus likely have utility and applicability to a range of men in similar situations. In addition, the sheer variety of strategies presented shows that men view their mental-health as connected to their physical health, their social connections, helping others, talking to others, and recognising the need for rewards, a sense of humour and, not being too hard on oneself. This concords with a previous Australian survey, which found that respondents rated lifestyle interventions (e.g., physical activity, relaxation) as likely to be helpful to promoting recovery in mental health [29].

Table 7 Multivariate hierarchical regression for symptoms of depression - PHQ-9 $(n=465)$

\begin{tabular}{|c|c|c|c|c|c|c|c|c|c|c|}
\hline & \multicolumn{5}{|c|}{ Model 1 management } & \multicolumn{5}{|c|}{ Model 2 management } \\
\hline & $\bar{B}$ & SE & Sig & Lower & Upper & $\bar{B}$ & SE & Sig & Lower & Upper \\
\hline Age & -.041 & .025 & .100 & -.091 & .008 & -.048 & .025 & .056 & -.098 & .001 \\
\hline Employment & -2.92 & .687 & $.000^{* *}$ & -4.27 & -1.57 & -2.75 & .681 & $.000^{* *}$ & -4.09 & -1.42 \\
\hline Relationship & -1.39 & .628 & .028 & -2.62 & -.151 & -1.55 & .623 & .013 & -2.77 & -.325 \\
\hline Education & -2.05 & .580 & $.000^{* *}$ & -3.19 & -.912 & -1.71 & .580 & $.003^{*}$ & -2.85 & -.565 \\
\hline Stressful events & 2.63 & .435 & $.000^{* *}$ & 1.78 & 3.49 & 2.71 & .430 & .000 & 1.87 & 3.56 \\
\hline Self-care strategies (M) & & & & & & .319 & .611 & .601 & -.881 & 1.52 \\
\hline Pleasure strategies (M) & & & & & & .709 & .591 & .230 & -.451 & 1.87 \\
\hline Achievement strategies (M) & & & & & & -.859 & .596 & .150 & -2.03 & .312 \\
\hline Cognitive strategies (M) & & & & & & -2.05 & .642 & $.002^{* *}$ & -3.31 & -.785 \\
\hline Connectedness strategies (M) & & & & & & -.872 & .630 & .167 & -2.11 & .366 \\
\hline$R^{2}$ & & & $.183^{* *}$ & & & & & $.219^{* *}$ & & \\
\hline$R^{2}$ change & & & $.183^{* *}$ & & & & & $.035^{* *}$ & & \\
\hline
\end{tabular}

${ }^{*} p<.01 ;{ }^{* *} p \leq .001$ 
Our results show an inverse relationship between participants' depression risk and the regular use of self-care (e.g., 'eat healthily' or 'exercise'), achievement (e.g., 'plan out my time' or 'set goals for the future') and cognitive (e.g., 'use humour to reframe my thoughts and feelings') prevention strategies. With regard to management strategies, the men in our sample reported that decreased symptoms of depression were significantly and independently related to regular use of cognitive strategies (e.g., 'notice my thought patterns and try to change my perspective'). This aligns with previous research showing that regular use of achievement strategies is associated with lower risk of depression $[9,10]$ and the overwhelming evidence demonstrating the effectiveness of cognitive therapies in reducing depression risk and depression symptoms [30-32]. Also consistent with previous research, our data showed that younger age and more stressful events were predictors of higher depression risk, while employment and higher levels of education predicted lower depression symptomology [33-38].

However, in contrast with previous research [37], we found that relationship status was not a significant predictor of either depression risk or depression symptoms in multi-variate analyses. Similarly, while regularly using self-care strategies (e.g., diet or exercise) were significantly associated with lower depression risk, the same relationship was not observed with depression symptoms. This is unexpected, given previous research which has emphasised the influence of poor quality diets $[39,40]$ and lack of exercise on mood [41], the clinical benefits gained with exercise [42], and recommendations to incorporate dietary improvements and increased physical activity into depression treatment plans [43-45]. It may be that our results simply reflect ongoing questions about the required nature of dietary improvements, or how much exercise is necessary to relieve depression symptoms. For example, a 2013 Cochrane review concluded that exercise has a small effect size and is no more effective than psychological or pharmacological therapies in reducing symptoms of depression [46]. A 2009 review emphasised that exercise routines typically only have a measurable effect on depression symptoms when routines are maintained over the long term [47]. Given the cross-sectional nature of our data, it is not possible to be certain how long the participants had been exercising for, which may account for the lack of an independent relationship with depression symptoms found.

In addition to the results of multivariate analyses, the survey found that, on the whole, the men reported a broad openness to using strategies they do not currently employ. For both prevention and management, more than $40 \%$ of the sample were open to seeing a health professional, joining a group, club or team, practising meditation, or mindfulness or gratitude, and in the case of management of low mood, setting goals for the future. Some conflicting views were also noted, for example, a majority reported being open to having a mentor or joining a group, while a minority held strongly opposing views (i.e., they would never use these strategies). However, with the exception of 'following faith, religion or spiritually', where the majority said they would never use this strategy, most participants either used, or were open to using, nearly all of the strategies in the survey. Openness to seeing a health professional is perhaps surprising, given previous reports that men can have negative attitudes towards help-seeking [10, 11, 48]. However, previous work has found that people rate GPs and counsellors as likely to be helpful for mental health disorders [29] and given that a majority of men in the sample had previous experience with depression, it is possible this contributed to their openness to seeking help [49].

\section{Clinical and public health implications}

Clearly, stressful events contribute to both depression risk and depression symptoms, yet experiencing stressful events is not always controllable. The present results are therefore important in providing insights into factors men can control, namely their choice and use of effective self-help strategies. The findings thus give rise to several important implications for clinical and public health practice.

Firstly, health professionals, families and friends supporting and treating men at risk of depression should note that while certain prevention strategies were significantly related to lower depression risk, the same strategies used for management were not significant predictors of fewer depression symptoms. Therefore, it is crucial to help men to match their use of strategies to different mental health aims. For example, diet, exercise, achievement and 'reframing' strategies were all important tools in preventing depression among 'at-risk' men in the absence of clinically significant symptoms. However, once symptomatic, men reported that managing symptoms through the use of cognitive reframing strategies was important - with the caveat that exercise may have a dose-response relationship with depression [50] and is thus important throughout all stages of care.

It may also be important to consider a man's level of conformity to traditionally 'masculine' belief systems. While the present survey did not assess men's gender role conformity, it is clear from previous research that adherence to masculine norms can 
influence men's attitude towards help-seeking [11, 51], and can affect which strategies they use in times of distress [8, 52]. Furthermore, adhering to masculine norms may be especially important to younger men [53]. Thus, developing an understanding of the relative importance of 'masculinity' to an individual's identity may significantly assist in successfully supporting men to self-manage their depression.

With regard to public health messaging, it may be prudent to publicise firstly men's use of and openness to using many different strategies. The men in this study used, on average, 16 prevention strategies and 14 management strategies, while 'taking time out' was the most common regularly-used management strategy. It would appear that it is important to men to be able to choose from a range of social, emotional, practical or problemsolving strategies at every level of symptom severity. Future public health campaigns targeting men could focus on encouraging men to try out new strategies that other men have found useful by publicising some of the strategies reported here. Secondly, public health messaging could emphasise that men make important distinctions between prevention and management when it comes to their mental health, with an emphasis on recognising when it is important to have some 'time out'. This may be an important message for men who are not in contact with health services. Hearing that other men use many different positive strategies to self-manage their mental health, and who also value the importance of taking time out during tough times, could help to normalise such self-care behaviours for men in the community.

Future public health and awareness campaigns might also highlight that men report being open to using 'non-traditional' strategies such as meditation, or finding a mentor, and that these types of strategies are worth trying, to see if they are useful. In this way, the present results may help to inform social-norm based education and health campaigns, by conveying simple messages about the positive strategies used by men to prevent and manage feeling "flat or down". The messages should highlight that men generated the strategies, use them and find them helpful. The information may help to give other men fresh ideas, or convince men to try positive strategies when previously they may have favoured unhelpful coping mechanisms. Simply hearing that other men consciously invest in preventing poor mental health could be a powerful message.

\section{Limitations and future research}

Among Australian men in 2007, the prevalence of a depressive episode in the previous 12 months was $3.1 \%$ [54]. Despite our efforts to publicise the study widely throughout Australia, in this sample, the majority of men were currently at-least mildly depressed (68\%), were also tertiary educated $(84 \%)$ at higher rates than the general population [55] and lived in metropolitan areas (80\%). Given these considerations, there may be further positive strategies used by men that haven't been represented in our survey and the results may not generalise to all men. In addition, regular use of a strategy was chosen as the unit of analysis, based on the assumption that regularly used strategies represent what is in a person's behavioural repertoire. However, we also acknowledge that some strategies may be effective with only occasional use. Future research would benefit from examining the best conceptualisation of 'frequency of use' and 'number of strategies used' as indicators of effective strategy use in men with depression. In addition, given the cross-sectional nature of the data presented, future research should consider using prospective studies to determine possible causal relationships between use of particular strategies and severity of depression symptoms.

Despite these limitations, it is worth noting that the study attracted a large sample of men across Australia, from a population who can be reticent about discussing their mental health. The results are therefore important in confirming earlier findings [19] and are vital to providing new insights into an under-researched area, namely, the positive things men do to prevent and manage their mental health.

\section{Conclusions}

The current findings demonstrate that the men in the study report that they currently use, and are open to using, a broad range of practical, social, emotional, cognitive, and problem-solving strategies to maintain their mental health. These findings are significant for men in the community who may not be in contact with professional health services and would benefit from health messages promoting positive strategies as effective tools in the prevention and management of depression.

\section{Availability of data and materials}

Data is available upon request.

\section{Appendix}

\section{Survey questions}

"Here is a list of 26 things men do:

1. Regularly to keep themselves feeling $\mathrm{OK}$, on an even keel, and in balance; and

2. In the specific times they are feeling down or going through a rough patch, in order to make themselves feel better." 
Do you do any of these things? Please respond to each strategy twice.

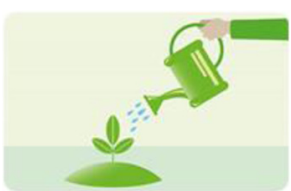

To keep myself feeling ok or on an even keel from day to day:

\begin{tabular}{|c|c|c|c|c|c|c|c|}
\hline do this & $\begin{array}{l}\text { I do this } \\
\text { occasionally }\end{array}$ & $\begin{array}{l}\text { I don't do this, } \\
\text { but think it's a } \\
\text { good idea }\end{array}$ & $\begin{array}{l}\text { I don't do this, } \\
\text { and I wouldn't } \\
\text { ever }\end{array}$ & $\begin{array}{l}\text { I do this } \\
\text { regularly }\end{array}$ & $\begin{array}{l}\text { I do this } \\
\text { occasionally }\end{array}$ & $\begin{array}{l}\text { I don't do this, } \\
\text { but think it's a } \\
\text { good idea }\end{array}$ & $\begin{array}{l}\text { I don't do this, } \\
\text { and I wouldn't } \\
\text { ever }\end{array}$ \\
\hline
\end{tabular}

Eat healthily

Exercise (alone or with others)

Change my sleeping habits to get either more or less sleep as needed

Reward myself with something I enjoy

Give myself some time out

See a health professional (e.g., doctor, counsellor, psychologist or psychiatrist)

Keep myself busy (e.g., with chores or hobbies)

Achieve something, whether big or small

Plan out my time or stick to a routine (e.g., having a daily 'to do' list)

Set goals for the future

Meditate, or use mindfulness techniques or gratitude exercises

Use positive self-talk

Focus on my 'life purpose'

Do something to help another person

Follow a faith, religion or spirituality

Talk to people close to me, or someone I trust when I have a problem

Hang out with people who are positive

Spend time with a pet

Join a group, club or team

Maintain a relationship with a mentor, or contact them when I'm feeling down

Accept my sad feelings and remember that 'this too will pass'

Remind myself that everyone messes up from time to time 


\begin{tabular}{|c|c|c|c|c|c|c|c|c|}
\hline $\begin{array}{l}\text { Notice my thought patterns and } \\
\text { try to change my perspective } \\
\text { (e.g., ask myself "Is there another } \\
\text { way of looking at this?") }\end{array}$ & - & • & - & - & - & - & - & - \\
\hline $\begin{array}{l}\text { Distract myself from negative } \\
\text { thoughts and/or feelings }\end{array}$ & - & - & - & - & - & - & - & - \\
\hline $\begin{array}{l}\text { Use humour to re-frame my } \\
\text { thoughts and feelings }\end{array}$ & - & - & - & • & - & - & - & . \\
\hline
\end{tabular}

Are there any other strategies that you use specifically to stay feeling pretty good or on an even keel and/or prevent yourself from feeling down? [FREE TEXT ANSWER]

Are there any other strategies that you use specifically to pick yourself up when you are feeling down or going through a rough patch? What are they? [FREE TEXT ANSWER]

\section{Abbreviations}

M: Mean; MDRS: Male depression risk scale; PHQ-9: Patient health questionnaire-9; SD: Standard deviation; SPSS: Statistical package for the social sciences.

\section{Competing interests}

The authors declare that they have no competing interests.

\section{Authors' contributions}

JP conceived of the study, led the team in the study's design, coordination and data collection, oversaw analyses and drafted the manuscript. ASF participated in the study's design and data collection, conducted data analyses and helped draft the manuscript. IM participated in the study's design and data collection, assisted with data analyses and helped draft the manuscript. SN participated in the study's design, assisted with data analyses and helped draft the manuscript. ELW participated in the study's design and data collection, and helped draft the manuscript. HC contributed to the conception and design of the study and helped draft the manuscript. MJP participated in the study's design and helped draft the manuscript. DH-P contributed to the conception and design of the study and helped draft the manuscript. KW contributed to the conception, design and coordination of the study and helped draft the manuscript. All authors read and approved the final manuscript.

\section{Acknowledgements}

This research project was funded by beyondblue with donations from The Movember Foundation. We would like to acknowledge the help given to the project by Roy Powell of Mensheds Australia and all of the men who participated in the research.

\section{Author details}

${ }^{1}$ Black Dog Institute, UNSW, Sydney, Australia. ${ }^{2}$ School of Public Health and Community Medicine, UNSW, Sydney, Australia. ${ }^{3}$ School of Psychiatry, UNSW, Sydney, Australia. ${ }^{4}$ Faces in the Street, St Vincent's Urban Mental Health and Wellbeing Research Institute, Sydney, Australia.

Received: 30 July 2015 Accepted: 7 November 2015

Published online: 16 November 2015

\section{References}

1. Centre for Disease Control. Suicide: facts at a glance. 2010. http://www.cdc. gov/violenceprevention/pdf/Suicide-DataSheet-a.pdf. Accessed 25 May 2015.

2. Australian Bureau of Statistics. Suicides 2005-3309.0. 2007. Australian Government. http://www.ausstats.abs.gov.au/Ausstats/subscriber.nsf/0/ 952361A2A29BDBB4CA25729D001C09CF/\$File/33090_2005.pdf. Accessed 25 May 2015.

3. Schrijvers DL, Bollen J, Sabbe BGC. The gender paradox in suicidal behavior and its impact on the suicidal process. J Affect Disord. 2012;138:19-26.
4. Fassberg MM, van Orden KA, Duberstein P, Erlangsen A, Lapierre S, Bodner E, et al. A systematic review of social factors and suicidal behavior in older adulthood. Int J Environ Res Public Health. 2012;9:722-45.

5. Van de Velde S, Bracke P, Levecque K. Gender differences in depression in 23 European countries. Cross-national variation in the gender gap in depression. Soc Sci Med. 2010;71:305-13.

6. Cavanagh A, Wilson CJ, Kavanagh DJ, Caputi P. EPA-0622 - Men's expression and experience of depression: a systematic review. Eur Psychiatry. 2014;29(Supplement 1):1.

7. Addis ME. Gender and depression in men. Clin Psychol Sci Pract. 2008;15:153-68.

8. Player MJ, Proudfoot J, Fogarty A, Whittle E, Spurrier M, Shand F, et al. What interrupts suicide attempts in men: a qualitative study. PLoS One. 2015;10:e0128180.

9. Brownhill S, Wilhelm K, Barclay L, Schmied V. 'Big build': hidden depression in men. Aust N Z J Psychiatry. 2005;39:921-31.

10. Hoy S. Beyond men behaving badly: a meta-ethnography of men's perspectives on psychological distress and help seeking. Int J Mens Health. 2012;11:202

11. Yousaf O, Popat A, Hunter MS. An investigation of masculinity attitudes, gender, and attitudes toward psychological help-seeking. Psychol Men Masculinity. 2015;16:234-7.

12. Harris MG, Diminic S, Reavley N, Baxter A, Pirkis J, Whiteford HA. Males' mental health disadvantage: an estimation of gender-specific changes in service utilisation for mental and substance use disorders in Australia. Aust N Z J Psychiatry. 2015;49(9):821-32. doi:10.1177/0004867415577434.

13. Yousaf $O$, Grunfeld EA, Hunter MS. A systematic review of the factors associated with delays in medical and psychological help-seeking among men. Health Psychol Rev. 2013:1-13. doi:10.1080/17437199.2013.840954.

14. Whittle EL, Fogarty AS, Tugendrajch S, Player MJ, Christensen H, Wilhelm K, et al. Men, depression, and coping: Are we on the right path? Psychol Men Masculinity. 2015;16:426-38. No Pagination Specified.

15. Munoz RF, Cuijpers P, Smit F, Barrera AZ, Leykin Y. Prevention of major depression. Annu Rev Clin Psychol. 2010;6:181-212.

16. Cuijpers P, van Straten A, Smit F, Mihalopoulos C, Beekman A. Preventing the onset of depressive disorders: a meta-analytic review of psychological interventions. Am J Psychiatry. 2008;165:1272-80.

17. van't Veer-Tazelaar PJ, van Marwijk HW, van Oppen P, van Hout HP, van der Horst HE, Cuijpers $P$, et al. Stepped-care prevention of anxiety and depression in late life: a randomized controlled trial. Arch Gen Psychiatry. 2009;66:297-304

18. World Health Organization, Geneva. Adherence to long-term therapies: evidence for action. 2003. http://www.who.int/chp/knowledge/publications/ adherence_report/en/. Accessed 25 May 2015.

19. Fogarty AS, Proudfoot J, Whittle EL, Player MJ, Christensen H, Hadzi-Pavlovic D, et al. Men's use of positive strategies for preventing and managing depression: a qualitative investigation. J Affect Disord. 2015;188:179-87.

20. Morgan AJ, Jorm AF. Self-help strategies that are helpful for sub-threshold depression: a Delphi consensus study. J Affect Disord. 2009;115:196-200.

21. van Someren MW, Jacobijn YFB, Sandberg AC. The think aloud method: a practical guide to modelling cognitive processes. London: Academic; 1994

22. QuestionPro. Online research made easy. 2013. http://www.questionpro. com/au/. Accessed 2 March 2015

23. Rice SM, Fallon BJ, Aucote HM, Möller-Leimkühler AM. Development and preliminary validation of the male depression risk scale: furthering the assessment of depression in men. J Affect Disord. 2013;151:950-8.

24. Kroenke K, Spitzer RL, Williams JB. The PHQ-9: validity of a brief depression severity measure. J Gen Intern Med. 2001;16:606-13. 
25. IBM. IBM SPSS statistics for windows, version 22.0. Armonk: IBM Corp; 2014.

26. Pallant J. SPSS survival manual. 3rd ed. Crows Nest: Allen \& Unwin; 2007.

27. Nolen-Hoeksema S. Emotion regulation and psychopathology: the role of gender. Annu Rev Clin Psychol. 2012;8:161-87.

28. Olesen SC, Butterworth P, Leach L. Prevalence of self-management versus formal service use for common mental disorders in Australia: findings from the 2007 National Survey of Mental Health and Wellbeing. Aust N Z J Psychiatry. 2010;44:823-30.

29. Reavley NJ, Jorm AF. Recognition of mental disorders and beliefs about treatment and outcome: findings from an Australian national survey of mental health literacy and stigma. Aust N Z J Psychiatry. 2011;45:947-56.

30. Beck AT. The current state of cognitive therapy: a 40-year retrospective. Arch Gen Psychiatry. 2005;62:953-9.

31. Dobson KS, Hollon SD, Dimidjian S, Schmaling KB, Kohlenberg RJ, Gallop RJ, et al. Randomized trial of behavioral activation, cognitive therapy, and antidepressant medication in the prevention of relapse and recurrence in major depression. J Consult Clin Psychol. 2008;76:468-77.

32. Dobson KS. A meta-analysis of the efficacy of cognitive therapy for depression. J Consult Clin Psychol. 1989;57:414-9.

33. Orth U, Robins RW, Meier LL. Disentangling the effects of low self-esteem and stressful events on depression: findings from three longitudinal studies. J Pers Soc Psychol. 2009;97:307-21.

34. Kendler KS, Karkowski LM, Prescott CA. Causal relationship between stressful life events and the onset of major depression. Am J Psychiatry. 1999:156:837-41.

35. Rice SM, Fallon BJ, Aucote HM, Moller-Leimkuhler A, Treeby MS, Amminger GP. Longitudinal sex differences of externalising and internalising depression symptom trajectories: Implications for assessment of depression in men from an online study. Int J Soc Psychiatry. 2015;61:236-40.

36. Kendler KS, Thornton LM, Prescott CA. Gender differences in the rates of exposure to stressful life events and sensitivity to their depressogenic effects. Am J Psychiatry. 2001;158:587-93.

37. Akhtar-Danesh N, Landeen J. Relation between depression and sociodemographic factors. Int J Ment Health Syst. 2007;1:4.

38. Bjelland I, Krokstad S, Mykletun A, Dahl AA, Tell GS, Tambs K. Does a higher educational level protect against anxiety and depression? The HUNT study. Soc Sci Med. 2008;66:1334-45.

39. Oddy WH, Robinson M, Ambrosini GL, O'Sullivan TA, de Klerk NH, Beilin LJ, et al. The association between dietary patterns and mental health in early adolescence. Prev Med. 2009:49:39-44.

40. Jacka FN, Mykletun A, Berk M, Bjelland I, Tell GS. The association between habitual diet quality and the common mental disorders in communitydwelling adults: the Hordaland Health study. Psychosom Med. 2011;73:483-90.

41. Jacka FN, Pasco JA, Williams L, Leslie ER, Dodd S, Nicholson GC, et al. Lower levels of physical activity in childhood associated with adult depression. J Sci Med Sport. 2011;14:222-6.

42. Craft LL, Perna FM. The benefits of exercise for the clinically depressed. Prim Care Companion J Clin Psychiat. 2004:6:104-11.

43. Jacka FN, Berk M. Depression, diet and exercise. Med J Aust. 2013;199:S21-3.

44. Babyak M, Blumenthal JA, Herman S, Khatri P, Doraiswamy M, Moore K, et al. Exercise treatment for major depression: maintenance of therapeutic benefit at 10 months. Psychosom Med. 2000;62:633-8.

45. Stathopoulou G, Powers MB, Berry AC, Smits JAJ, Otto MW. Exercise interventions for mental health: a quantitative and qualitative review. Clin Psychol Sci Pract. 2006;13:179-93.

46. Cooney GM, Dwan K, Greig CA, Lawlor DA, Rimer J, Waugh FR, et al. Exercise for depression. Cochrane Database Syst Rev. 2013;9:CD004366. doi:10.1002/14651858.CD004366.pub6.

47. Mead GE, Morley W, Campbell P, Greig CA, McMurdo M, Lawlor DA. Exercise for depression. Cochrane Database Syst Rev. 2008;4:CD004366. doi:10.1002/14651858.CD004366.pub3.

48. Cotton SM, Wright A, Harris MG, Jorm AF, McGorry PD. Influence of gender on mental health literacy in young Australians. Aust N Z J Psychiatry. 2006:40:790-6.

49. Skärsäter I, Dencker K, Häggström L, Fridlund B. A salutogenetic perspective on how men cope with major depression in daily life, with the help of professional and lay support. Int J Nurs Stud. 2003;40:153-62.

50. Hamer M, Stamatakis E, Steptoe A. Dose-response relationship between physical activity and mental health: the Scottish Health Survey. Br J Sport Med. 2009:43:1111-4.
51. O'Brien R, Hunt K, Hart G. 'It's caveman stuff, but that is to a certain extent how guys still operate': men's accounts of masculinity and help seeking. Soc Sci Med. 2005;61:503-16.

52. Granato SL, Smith PN, Selwyn CN. Acquired capability and masculine gender norm adherence: potential pathways to higher rates of male suicide. Psychol Men Masculinity. 2014;16:246-53. No Pagination Specified.

53. Rice S, Fallon B, Bambling M. Men and depression: the impact of masculine role norms throughout the lifespan. Aust Educ Dev Psychol. 2011;28:133-44.

54. Australian Bureau of Statistics. National survey of mental health and wellbeing 2007-4326.0. 2008. http://www.abs.gov.au/ausstats/abs@.nsf/ Latestproducts/4326.0Main\%20Features12007? opendocument\&tabname= Summary\&prodno $=4326.0 \&$ issue $=2007 \&$ num $=\& v i e w=$. Accessed 19 Aug 2014.

55. Australian Bureau of Statistics. 4102.0 - Australian social trends. 2008. http://www.abs.gov.au/AUSSTATS/abs@.nsf/Lookup/4102.0Chapter6002008. Accessed 27 July 2015

\section{Submit your next manuscript to BioMed Central and take full advantage of:}

- Convenient online submission

- Thorough peer review

- No space constraints or color figure charges

- Immediate publication on acceptance

- Inclusion in PubMed, CAS, Scopus and Google Scholar

- Research which is freely available for redistribution 